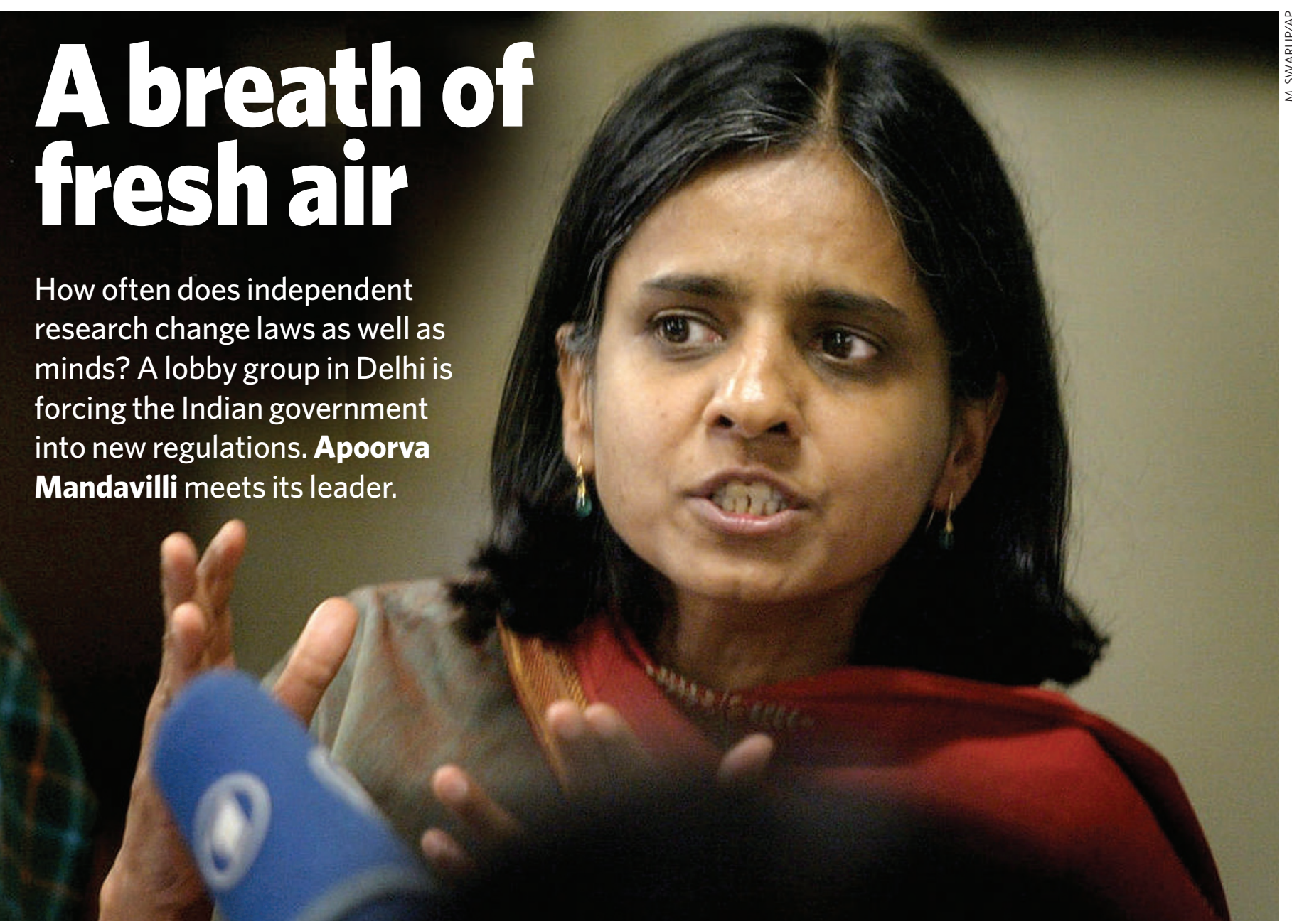

$\Lambda$ decade ago the city of Delhi was choking. Fumes from the growing traffic rendered the air thick and foul with toxic chemicals, earning India's capital city the dubious distinction of being the fourth most polluted city in the world. Levels of fine particles in the air were nearly 17 times higher than the permissible maximum. You could almost feel them as you breathed.

Visit Delhi today, and the difference is palpable. Green-striped buses and auto rickshaws rush past powered by compressed natural gas. Levels of sulphur in diesel have been brought down from 2,500 parts per million to 500 parts per million. Concentrations of particles in the air are still three times the national standard, but more bearable - the air feels unmistakably cleaner.

The improvement is largely due to the efforts of one small non-governmental organization, the Centre for Science and Environment (CSE). Founded by the science journalist Anil Agarwal in 1980, the Delhi-based group launched a relentless campaign in 1996 to replace diesel in Delhi's public transport with a cleaner fuel: compressed natural gas. Its headline-grabbing tactics were what you might expect from a group founded by a science journalist: at one point it hired a booth at a Delhi car show and offered attendees lung tests. In April 2002, after years of legal battles, India's Supreme Court forced Delhi's public vehicles to switch to compressed natural gas. "It's undoubtedly one of the most influential organizations in the country," says Mahesh Rangarajan, a former Rhodes scholar and commentator on Indian politics based in Delhi.

So how did a small band of campaigning journalists evolve into a respected environmental pressure-group powerful enough to change laws and send multinational companies running for cover? The CSE is that rare entity, an activist group that is prepared to back up its campaigns with its own research. India has countless problems, but the CSE picks its fights wisely. For the past 20 years, it has focused on five main areas: air pollution, climate change, water management, pesticides and poverty eradication.

Today the CSE has a charismatic woman at its head in Sunita Narain, who took over the reins of the organization in 2002 after the death of Agarwal. "We are essentially playing the role of a watchdog, pushing for policy and being a public advocate," she says. "We have the arrogance to believe we are as powerful as government."
Most recently, the CSE has taken on the softdrinks giants Coca-Cola and PepsiCo. In August 2006, the CSE released a technical analysis of 12 popular soft drinks made by these companies and sold in India, claiming that they contained toxic pesticides, including lindane, DDT, malathion and chlorpyrifos, at up to 36 times the European standards for bottled water.

In a testament to the organization's credibility, four Indian states promptly banned sales of soft drinks made by Coca-Cola and PepsiCo at schools, government-owned offices and hospitals, with one state imposing a total ban on sales and production. Sales of Coca-Cola products nationwide fell by about $18 \%$.

As in other CSE campaigns, the battle was waged on two fronts. Articles reporting the results appeared in the CSE's fortnightly magazine Down to Earth, while the technical data generated by three staff scientists were posted on the CSE's website.

"To my mind, that's what makes them powerful," says David Dickson, director of UK-based SciDev.net, an online science information resource for the developing world. "I'm not saying all their science is perfect, but I think they realize the importance of having science behind 
their argument. That differentiates them from many other environmental groups."

Agarwal played the research card from the start. A mechanical engineer by training, Agarwal's career as a journalist stretched from Indian newspapers to UK publications including Nature and New Scientist. Returning to India in 1980, Agarwal launched the CSE with two fellow journalists. They began by researching environmental issues, looking at poverty and resource management at the village level and putting together the first of the ambitious series of 'Citizen's Reports' published under the general title State of India's Environment.

At that time, environmental issues were discussed only in developed countries, or as Narain puts it: "First you get rich, then you pollute, then you get dirty, then you start cleaning up." But Agarwal argued that India was too poor not to care about the environment. "He was putting environmental issues on the development agenda and he was doing it at a time when most people weren't," says Dickson.

\section{Hard graft}

The material for those first reports was gathered painstakingly. Narain, who joined the CSE in 1981 as a volunteer, and her colleagues collected newspaper articles, literature from non-governmental organizations and scientific papers. They also wrote to scientists for more information. "The task was to take all that, assimilate it, analyse it and find a trend. It was massive," recalls Narain.

Right from the first report in 1982 it was apparent that the CSE had found a winning formula. The report gained acco-

lades from the international press, stirred Tunisia to launch its first environmental ministry and inspired Lester Brown of the Worldwatch Institute in Washington DC to launch his annual State of the World reports.

A 1991 report by the CSE linking monsoon flooding with deforestation also helped transform the environmental debate in India. Although the CSE wasn't the first to make the link, its report consolidated research and traditional knowledge and presented it in accessible language, says P. V. Unnikrishnan, humanitarian coordinator for ActionAid in Asia. "In 1991 for such a report to come out, touching on such a controversial issue, was very good. It helped kickstart an informed debate."

Although generating its own research gets the CSE attention, it also means that its research can become the focus of criticism. For example, its reports on pesticides in soft drinks were attacked on technical grounds from the start by both the multinationals involved and the Indian government. This high-profile fight has earned Narain the moniker of 'Coke lady' and has gained the CSE fame beyond Delhi.

\section{Standard bearer}

Narain is used to public criticism, but she admits the soft-drinks fight has been much nastier than she expected - and the CSE got into it almost by accident. The organization became interested in general water-safety standards in 2002, when it tested ten brands of bottled water and found pesticides in them. Puzzled by the vehemence with which CocaCola and PepsiCo, which had some of the purest bottled water, were fighting demands for water standards, the CSE decided to look at pesticide levels in soft drinks. "We just tested out of curiosity, but now that we're in it, we can't back off," Narain says.

Nevertheless, Narain says her main gripe isn't with Coca-Cola or PepsiCo, but with the government, which has dragged its feet in setting safety limits for pesticide residues in soft drinks. "Even now, our only demand from the government is standards," says Narain. "We found something that's unclean. Clean it up. We want standards. Simple."

Most countries, including India, have standards for pesticide levels in the water that goes

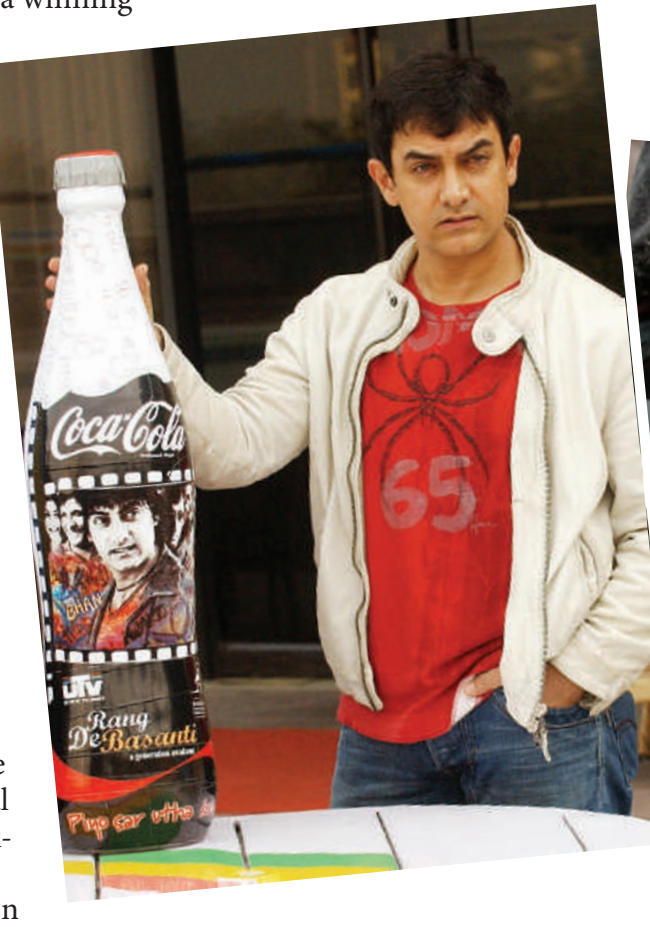

into carbonated drinks but not for the product itself. That may be acceptable in countries where the raw material is relatively clean, but not in India, Narain argues. The solution, she says, is for India to implement testing of the final products.

The CSE released its initial findings on pesticides in soft drinks in 2003. After initially disparaging the group's methods, the government set up a Joint Parliamentary Committee - only the fourth in India's history - to investigate.

The committee upheld the CSE's methods and findings and asked the Bureau of Indian Standards to review soft-drinks standards. Two years later, the bureau set new pesticide limits, which the CSE welcomes. But it has yet to make them law - thanks, Narain alleges, to interference from the soft-drinks industry.

\section{Imperfect harmony}

Coca-Cola and PepsiCo are both standing by their products, saying that their soft drinks made in India are of the same quality as anywhere else. The companies maintain that setting standards is complicated because there are no reliable tests to assess pesticide levels in carbonated beverages. "Measuring for the pesticides [in a final product] is very difficult to do," says Kari Bjorhus, a spokeswoman for Coca-Cola in Atlanta, Georgia.

The CSE data have not been peer reviewed but scientists contacted by Nature say that the organization followed methods accepted by bodies such as the US Environmental Protection Agency. "The data are believable and the levels they find [of pesticides] are believable," says Laura McConnell, a research chemist for the US Department of Agriculture's research service. "These should be

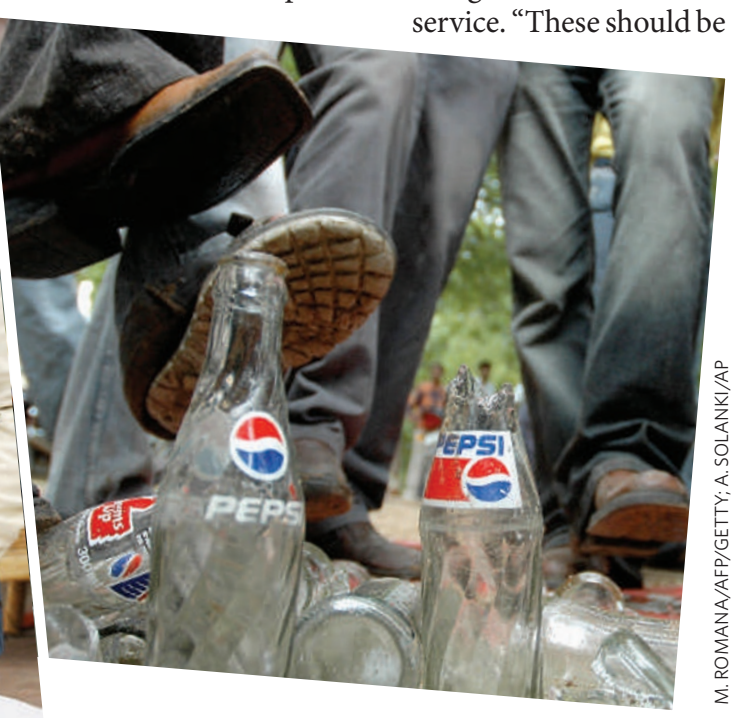

Coca-Cola has recruited actor Aamir Khan (left) to boost its image, while students protest by smashing bottles. 
values that would stand up in court as valid." McConnell also questions the soft-drinks companies' claim that testing for pesticides is complicated. "I don't think it's that complex," she says.

After the 2003 report, Coca-Cola approached the UK government's Central Science Laboratory (CSL), which tested 180 samples and reported that pesticide levels in the soft drinks were below "acceptable" limits for drinking water. But, Narain says, the lab never released the detailed reports or chromatograms for scrutiny. Bjorhus confirms that the CSL did not release its full data to the public, but she argues that the lab didn't find any pesticides, "so there is nothing to review in terms of findings". She notes that the CSL is "one of the most respected laboratories in the world and their integrity is unquestioned".

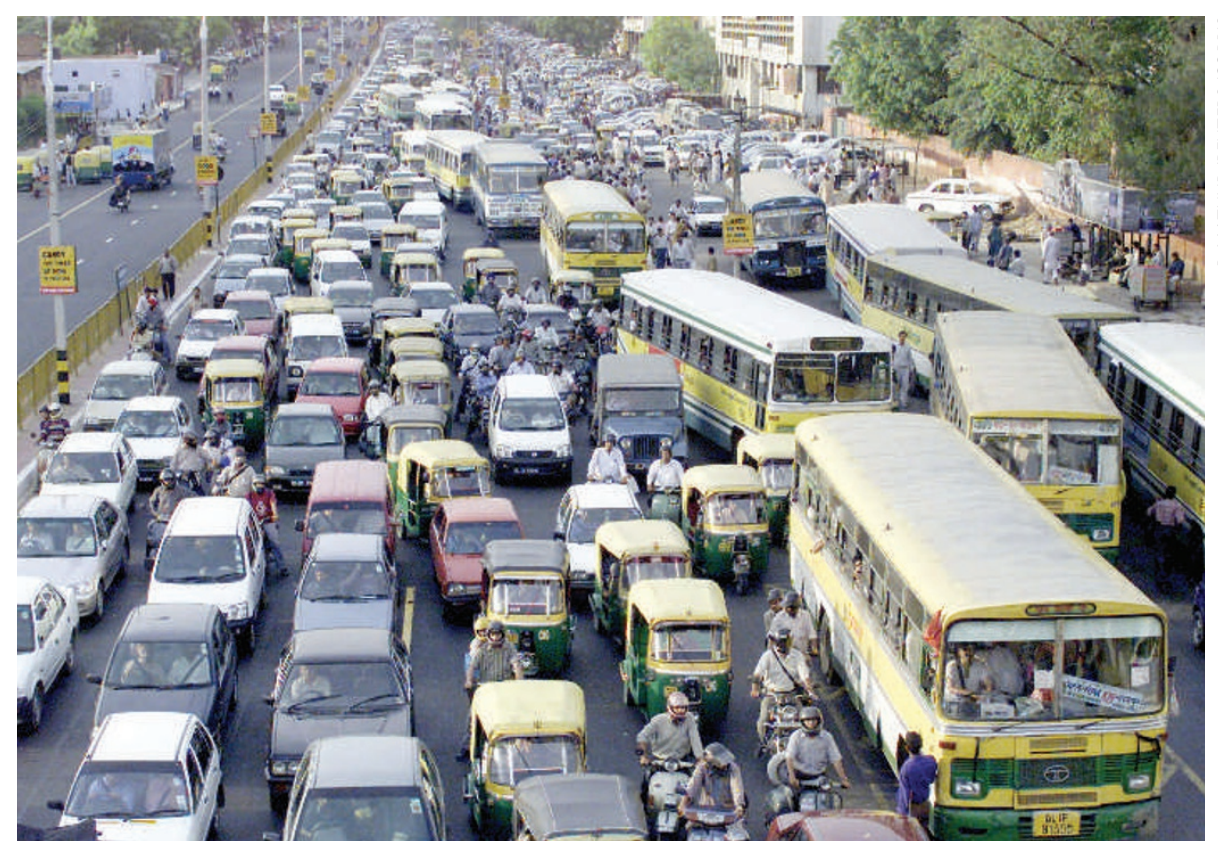

The Centre for Science and Environment forced Delhi's public transport to switch from diesel to gas.
The UK laboratory's report has not yet persuaded Indian state governments that the drinks are safe, and they remain banned in many schools and state-run institutions. The pesticide battle has also fuelled a wider resentment in India against multinational companies, with people smashing up drinks bottles. In response, Coca-Cola has launched an expensive media campaign, featuring top movie stars such as Aamir Khan vouching for the drinks' safety. But Narain says, "their sales are still down, Aamir Khan or no Aamir Khan".

\section{Close focus}

Away from the media battle, the technical arguments over safety are now focused on the validity of different tests. After the CSE released its 2006 report, assessing 25 new soft-drink samples for pesticides, PepsiCo's president Indra Nooyi visited India in December, saying that the two multinationals would work

"We are not asking
for closure of Coke
and Pepsi. We just
want standards."
- Sunita Narain

"We are not asking

and Pepsi. We just

- Sunita Narain in science. But it wasn't until 1992 that Agarwal launched the magazine Down to Earth, backed by the belief that journalism is one of the most powerful ways to change things in India. Today, the magazine has a popular website and 20,000 paying subscribers. Like Agarwal, Narain sees herself as a journalist first, and is not afraid to attack those scientists who, she says, stay on the sidelines or sell their expertise to companies. She once wrote an editorial criticizing the scientific community for its "arrogance and ignorance, both completely unacceptable”.

Scientists have in turn criticized the CSE. In 2005, Narain was asked to head the Tiger Task Force, which looked into the controversies inherent in human and tiger coexistence and advised on tiger conservation. The final report left a lot to be desired, says biologist Ullas Karanth of the Wildlife Conservation Society, India, but he was impressed with Narain's hard work and willingness to change her mind together to find "a breakthrough science-based method to reliably and consistently measure the levels in finished products".

Coca-Cola and PepsiCo have commissioned AOAC International, an independent not-forprofit American scientific association, to review about 17 available analytical methods and to make recommendations to the Indian government. The report is expected in February.

Narain maintains that she would be willing to accept evidence showing the CSE's science to be wrong, but that the companies or the government have to provide it first. "We are not asking for closure of Coke and Pepsi, we are not interested in them as companies," says Narain. "We just want standards."

Today the CSE employs 125 journalists and researchers, about half of whom hold degrees when confronted with new evidence. "She's a person who in the end accepts science."

Soon after the launch of Down to Earth, the CSE embarked on its anti-pollution campaign in Delhi and on one of its other top priorities - water. The organization helped communities use traditional know-how to collect and store rainwater. "When we began advocating this solution in the mid-1990s, people laughed at us, basically said we were idiots, that this was not a solution for the scale of India," says Narain. "Today, nobody will argue that with you."

Passionate about every aspect of her work, Narain is harder to pin down on personal questions. On the sunny day I visit the CSE offices, Narain is rushing about barefoot in her office, laughingly deflecting the conversation from her personal life. "I'm the world's most boring person. I come to work, I go to sleep, I know nothing else," she says.

In addition to answering my questions, Narain juggles other visitors, including local student journalists, frequent updates on the lawsuits the CSE is embroiled in, a television interview, and a domestic crisis precipitated by a fallen tree in front of her house.

Narain comes from one of Delhi's illustrious families: her grandfather was an eminent journalist and his brother a gandhian freedom fighter. Her father, also a young freedom fighter, died when she was eight, leaving her mother to bring up Narain and her three sisters.

Narain joined the CSE straight after school and pitched into whatever tasks were most urgent. She says Agarwal was a tough boss - she is reputed to be one herself - tearing up copy until the writers got it just right.

Agarwal was known for his intelligence and integrity, but many say privately that Narain can be more open-minded and has given the CSE a friendlier profile. Some even suggest she is too soft on the government - and too cosy with government insiders. Among Narain's friends, for instance, is prime minister Manmohan Singh's daughter. Such personal attacks offend Narain: "Who cares if I am well connected? I haven't gone to Manmohan Singh to ask for a job."

Narain may flinch at personal attacks but remains undeterred in her work. When I met her, she had just returned from Ahmedabad, the second city where the CSE has successfully pushed for a switch to compressed natural gas. "We've been fighting for two years to clean Ahmedabad's air," she says. "Yesterday, the air in Ahmedabad was clean. It's worth it."

Apoorva Mandavilli is Senior News Editor for Nature Medicine.

See Editorial, page 683. 